\title{
Interdisciplinary research in practice at CMD, Uppsala University
}

\author{
Bengt L. Sandblad \\ CMD, Center for Human-Computer Studies \\ Uppsala University \\ Lägerhyddvägen 18, S-752 37 Uppsala, Sweden \\ Phone: +46 181833 21, E-mail: Bengt.Sandblad@cmd.uu.se \\ http://www.cmd.uu.se
}

\begin{abstract}
CMD, Uppsala University Center for Human-Computer Studies, is an interdisciplinary research unit where researchers from different departments of the university closely co-operate in research concerning computer applications in working life. Scientific disciplines such as psychology, computer science, systems analysis, physics, ergonomics, medicine and dentistry are represented. Main characteristics of the research are integration of different HCIrelated competencies into a homogenous interdisciplinary team and the strong involvement in 'real working life' development projects. Through this, new integrated theories, methods and techniques have been developed.
\end{abstract}

KEY WORDS Interface design, participatory design, cognitive load, development tools, work environment problems, $\mathrm{HCI}$ in organisations.

\section{THE INTERDISCIPLINARY EXPERIENCE}

Research concerning the introduction of information technology in working life must by necessity be interdisciplinary. However, the advantages of interdisciplinary research can only be achieved if it is paired with strong intradisciplinary competencies. If the researchers co-operating in the interdisciplinary research do not continuously develop their traditional knowledge, the interdisciplinary advantage will soon be lost. It also takes time and efforts to develop functioning interdisciplinary research co-operation. Success requires long time engagement, mutual respect, scientific methodology and, at least in the beginning, focus on concrete applications. Interdisciplinary knowledge is more then 'the sum of the parts'. At CMD, we have in this way been able to develop new approaches to studies of human-computer interaction in working life applications. Examples are methods for analysis of skilled professionals' every day use of information and methods and tools for design and construction of efficient user interfaces to be used in dynamic work situations.

\section{WORKING LIFE APPLICATIONS}

At CMD, the research focus is on working life applications of information technology. When developing computer systems for skilled professionals in different work environments, the role of the user interface is especially central. Badly designed interfaces will result in low user acceptance, high costs, inefficient work, negative stress and sometimes even health problems (Nygren, 1992). Interface requirement specifications for specific professional use will often differ significantly from more general design rules. Domain specific style guides, specifying interaction requirements for advanced use in specific work environments can significantly improve the design process. If the work organisation, the functionality of the computer support system or the user interface to the system is not properly designed, the possibilities for the professionals to perform efficiently will often be drastically reduced. We call such hindrances cognitive work environment problems. Research and field studies at CMD indicate that such problems are becoming increasingly important in today's working life. 


\section{COGNITIVE WORK ENVIRON- MENT PROBLEMS}

\begin{abstract}
A main research goal is to identify new knowledge concerning cognitive work environment problems and to specify system development methods and techniques that can minimise such problems. Research activities include experimental studies of cognitive work load and relations to design of user interfaces. Prototypes have been developed and tested in working life applications. (Nygren, 1996)
\end{abstract}

\section{RESEARCH AREAS}

In order to integrate traditional academic research with the introduction of improved methods and techniques in practical interface design and system development, our 'in house' laboratory research is combined with participation in 'real life' development projects. In such projects our research results can be tested in evaluated.

\section{New interface methods and techniques}

- Formulation of a method for analysis of information utilisation in professional work situations. The result of such an analysis is a set of requirement specifications for the interaction between user and system.

- Development of methods for specification of domain specific style guides for defined classes of work situations. In a domain specific style guide we incorporate high level design knowledge into interface element classes and related design rules (Borälv, 1994).

- The development of graphical user interfaces is today too resource consuming and leads to severe constraints when it comes to the use of experimental techniques. We are developing a prototype for object oriented, model based, user interfaces. Here the design and functionality of the system is described in a declarative language, stored in a database and interpreted at run-time.

- Several research activities concern aspects of visualisation techniques, such as e.g. the use and interpretation of colours in user interfaces and dynamic visualisation in virtual reality (VR) environments.

\section{Operator-Process interaction}

Research is here directed towards analysis of human capabilities and technological conditions for control of complex, dynamic systems. Operator support systems must allow development of efficient mental models of the process and support complex decision making. Application projects concern present problems in train traffic control and in control of high speed crafts at sea.
Next generation operator systems will be based on 'control by awareness' rather then 'control by exception'.

Organisational development and IT design

There is a need for a new paradigm of system development, focusing on development of organisation and work activities as such. Methods for analysis, requirement specifications, system design and construction, must consider all relevant aspects simultaneously, and not focus only on technical information support systems. We are currently, in co-operation with the Swedish National Tax Board, studying organisational development in a case handling domain, integrating development of organisation, information systems and professional competencies (Gulliksen, 1996).

\section{Usability evaluation methods}

In co-operation with occupational health care units we have developed a practical method for 'semi-expert' usability evaluation of existing computer systems in a work environment. The method is based on a combined observation and interview technique, and focuses on functionality and cognitive aspects of human-computer interaction.

\section{EDUCATIONAL PROGRAMS}

CMD is active in undergraduate programs at the university, where interdisciplinary courses are given e.g. in the computer science programs. Graduate students at CMD participate in the programs of their 'home' departments of the university, e.g. in the systems analysis and psychology programs.

\section{REFERENCES}

Nygren E., Johnson M., Lind M. and Sandblad B. The art of the obvious. Proceedings of $\mathrm{CHI} 92$, Monterey, California, May 1992.

Borälv E., Göransson B., Olsson E. and Sandblad B. Usability and efficiency. The HELIOS approach to development of user interfaces. Comp. Methods and Programs in Biomed.45, Suppl.(1994), S1-152.

Nygren, E. From paper to computer screen. Human information processing and user interface design. Ph.D. thesis. Faculty of Science and Technology, Uppsala, Sweden (1996). ISBN 91-554-3699-4.

Gulliksen, J. Designing for usability - Domain specific human-computer interfaces in working life. Ph.D. thesis. Faculty of Science and Technology, Uppsala, Sweden (1996). ISBN 91-554-3700-1. 